\title{
"We could be in touch with real classroom interaction": profissionais em formação em salas de aula de língua inglesa ${ }^{1}$
}

\author{
Isabel Cristina Rangel Moraes Bezerra \\ UERJ
}

\begin{abstract}
Resumo
Este trabalho reúne reflexões sobre o estágio supervisionado de inglês articulado a questões teóricas que envolvem o trabalho docente. A Prática Exploratória é o viés que encaminha a reflexão e a busca por entendimentos sobre tornar-se professor de inglês.

Palavras-chave: formação docente, Prática Exploratória, ensino de inglês, estágio supervisionado
\end{abstract}

\begin{abstract}
This paper combines reflection about the practicum activities developed by a selection of pre-service teachers and theoretical aspects of EFL teaching. Exploratory Practice is the approach chosen to conduct not only the reflexive process, but also the work for understanding on becoming an English teacher.
\end{abstract}

Keywords: teacher education, Exploratory Practice, English teaching, practicum.

\section{INTRODUÇÃO}

A formação inicial/continuada de professores de língua estrangeira tem sido foco constante de interesse de pesquisadores em Linguística Aplicada (Barcelos, Abrahão, 2002; Gimenez, 2004; Moraes Bezerra e Miller, 2006). Consequentemente, pensar o estágio supervisionado enquanto lugar de construção de reflexão sobre o contexto escolar e da percepção de que é impossível desassociar teoria da prática torna-se relevante contribuição a esta área. Isto se dá especialmente porque trata-se de ouvir licenciandos, ou professores alunos, que estão ocupando um entrelugar no percurso profissional em que, embora ainda sejam alunos, já ensaiam seus primeiros passos profissionais a partir de uma prática que se quer teoricamente informada, distanciandose de um modelo de formação dogmática (Moita Lopes, 1996).

Considerando-se tais questões, o presente artigo está dividido em três seções. Na primeira explicito como a disciplina Estágio Supervisionado de Língua Inglesa II 
(ESLI-II) é proposta e descrevo as atividades desenvolvidas com/pelos licenciandos durante o período de estágio nas escolas da rede pública de ensino. Ainda nesta seção, remeto essas questões a autores e às suas teorizações, fundamentando meu olhar de praticante exploratória (Miller, 2001; Allwright e Hanks, 2009). Na segunda seção, apresento fragmentos de alguns relatórios dos licenciandos referentes às atividades de

estágio. Analiso, através de suas colocações, como se dá a construção de saberes profissionais dos licenciandos no processo de reflexão sobre o percurso de estágio nas salas de aula. Neste momento, tento identificar possíveis influências de todo o percurso de formação da universidade, e desta disciplina em particular, para a formação inicial. Na terceira seção, apresento alguns entendimentos sobre as aulas e sobre o percurso de estágio vivenciado por nós.

\section{ESTÁGIO PARA QUEM E PARA QUÊ?}

O processo de formação inicial docente passa necessariamente pelo momento em que o licenciando encontra-se, a partir de uma outra perspectiva, com a sala de aula e com todos os atores sociais que nela transitam, visto que envolve-se na construção de um olhar àquele espaço e aos processos que ali se desenrolam não mais como o aluno de ensino fundamental ou médio, mas como profissional em formação. Todos trazem para estes contextos suas histórias de vida, suas crenças, seus entendimentos provisórios sobre o que significa ensinar e aprender uma língua estrangeira (LE). Em sua bagagem acadêmica, o professor aluno traz não apenas seus entendimentos sobre a língua estrangeira e sobre como ensiná-la construídos a partir de teorias da área. Traz, da mesma forma, suas crenças calcadas em suas vivências enquanto aluno ou mesmo enquanto professor em contextos como cursos de idiomas,escolas particulares ou aulas particulares.

Embora a ementa da disciplina ESLI-II seja eminentemente voltada para a prática docente em escolas de ensino médio, decidi adicionar a ela o aprofundamento de leitura de textos na área de Lingüística Aplicada². O objetivo desta decisão foi propiciar ao licenciandos mais um espaço para a construção de uma prática docente teoricamente informada, bem como para a reflexão desses docentes iniciantes sobre essa prática em construção. Além disso, eu buscava entender, a partir dos pressupostos da Prática Exploratória (PE), como se desenvolvia este processo. Interessava-me por entender se e de que maneira as aulas colaboraram para que os professores alunos construíssem um 
referencial teórico que funcionasse como um suporte para sua prática iniciante. Ademais, queria entender como os licenciandos conseguiam entender o que mapeavam na dinâmica em sala de aula durante suas observações e o porquê das explicações que forneciam acerca de suas decisões durante as aulas de co-participação e prática. Ressalto que não me impelia uma proposta tecnicista voltada para o domínio de micro habilidades para o ensino, mas uma tentativa de construção de saberes docentes para o mundo do trabalho que envolvesse um olhar aos contextos macro e micro social de atuação do professor de língua inglesa. Assim, os princípios da PE balizaram o caminhar da professora e pesquisadora praticante exploratória, guiando meu olhar e minhas decisões, fundamentando as propostas de atividades, em especial o relatório de estágio a partir das questões propostas como um outline para registro e reflexão dos professores alunos. Obviamente, os professores alunos eram colegas exploratórios, sendo incentivados a colaborar na condução do processo e a planejar suas aulas para entender questões de sala de sala de aula, sempre que o professor regente da turma de estágio permitisse.

Para que se entenda a proposta da Prática Exploratória é preciso vê-la como “um paradigma de pesquisa do praticante profissionalmente viável” (Gieve e Miller, 2006) em que ensino e aprendizado são feitos, podendo envolver, da mesma forma, um viés de reflexão e de pesquisa docente. Os praticantes envolvidos buscam construir entendimentos locais acerca de questões que lhes interessem, geralmente envolvendo a qualidade da vida em sala de aula (Gieve e Miller, 2006), estendendo-a para questões de ensino-aprendizado (Kuschnir e Machado, 2003; Silva, 2008), formação de saberes docentes (Miller, 2001; Moraes Bezerra, 2007b; Filipe, 2009), dentre outras. Os princípios da PE não devem ser entendidos como regras a serem seguidas, mas como eixos norteadores do caminhar reflexivo, apontando para uma perspectiva ética na forma como ver o 'outro' com o qual se vivencia e desenvolve a experiência de ensinaraprender e de refletir-pesquisar, posto que todos são praticantes exploratórios, não havendo sujeitos de pesquisa. Por outro lado, a sequência na qual os princípios são listados não indica o estabelecimento de uma ordem de importância na qual o primeiro seria mais importante do que o último deles.

Apresento em seguida tais princípios, conforme Miller et al (2008:147), adicionando comentários sobre como eles podem ser entendidos na configuração de prática docente/pesquisa/reflexão através da PE: 
- Priorizar a qualidade de vida - diz respeito à natureza das relações vivenciadas na e pela comunidade de aprendizagem/reflexão. Assim, interessa aos praticantes entenderem os processos discursivos de construção das relações entre os membros de forma a tentar aferir a qualidade de tais relações e como elas interferem nos processos pedagógicos e reflexivos.

- Trabalhar para entender a vida na sala de aula ou em outros contextos profissionais - visto que não se prioriza um 'agir para mudar', mas um 'agir para entender', antes de se partir para soluções ou mudanças em relação a conflitos ou problemas.

- Envolver todos neste processo - uma vez que o contexto pedagógico/profissional é entendido como um lócus de integração, todos os participantes são incentivados a participar das ações reflexivas.

- Trabalhar para a união de todos - sem ignorar a existência de conflitos e, muitas vezes, a dificuldade em administrá-los, a 'ação para entender' proposta pela PE se constrói no sentido da redução da assimetria institucional e contextualmente estabelecida entre os praticantes (professores, alunos, coordenadores, diretores, etc.). Segundo Santiago (2009:39), ao explicitar o ponto de vista do grupo de PE, “A união é a base do que fazemos, não desejamos chegar a lugar nenhum sozinhos, acreditamos na perspectiva do conjunto”.

- Trabalhar para o desenvolvimento mútuo - o trabalho para entender, na perspectiva da PE, deve propiciar a construção de entendimentos por parte de todos de forma que não apenas o professor - mas também os aprendizes, o consultor ou qualquer outro praticante - atinja níveis de compreensões e saberes diferentes ou mais profundos do que aqueles com os quais iniciou o processo. É a colaboração que pode gerar entendimentos para todos, sendo que tais entendimentos são de ordem pessoal, pois dizem respeito a como cada um se posicionou e agiu discursivamente durante todo o processo face aos posicionamentos e ações discursivos dos outros praticantes.

- Integrar este trabalho com as práticas de sala de aula ou com outras práticas profissionais - para não tornar o trabalho de reflexão/investigação uma tarefa extra, as práticas docentes são integradas às práticas de reflexão. São desenvolvidas Atividades Pedagógicas com Potencial Exploratório (Moraes Bezerra, 2003; Miller et al (2008) - as ARPEs - ou as Atividades de Reflexão com Potencial Exploratório (Moraes Bezerra, 2007) - as ARPEs) que consistem em atividades normalmente utilizadas para promover o ensino e/ou a reflexão/investigação do grupo quando os praticantes se engajam no processo de responder aos seus puzzles, i.e., aos questionamentos surgidos na dinâmica da vida escolar.

- Fazer com que o trabalho para o entendimento e a integração sejam contínuos - isso significa a construção de uma atitude exploratória constantemente voltada para a discussão de crenças, para o partilhar de 
desabafos e desafios, para incentivar a criatividade, a curiosidade e o prazer (Miller et al., 2008). Assim sendo, o 'trabalho para entender’ não pode limitar-se a projetos com datas para seu início e término. Precisa estar sincronizado com o calendário dos interesses particulares dos praticantes e, ao mesmo tempo, integrado às práticas de ensinar e aprender, refletir e investigar.

Considerando-se a experiência dos professores alunos cujos fragmentos dos relatórios serão analisados nesta pesquisa, não houve apenas a vivência da ida às escolas campo de estágio. Houve, paralelamente a este percurso, por conta de minha decisão, um trabalho reflexivo, apoiado na perspectiva da PE apresentada acima, envolvendo discussão de textos e de acompanhamento para que pudessem dirimir dúvidas, sendo auxiliados no planejamento de aulas e de atividades para as turmas. Enquanto professora da disciplina e buscando delinear o curso a partir dos entendimentos que tenho co-construído com alunos e colegas ao longo dos últimos anos, fundamentados pelos princípios e pressupostos teórico-metodológicos da Prática Exploratória (Allwright 2005, 2003; Miller, 2001; Miller et al., 2008; Moraes Bezerra, 2007b, 2003), pedi ajuda aos licenciandos no sentido de construirmos um adendo à ementa que refletisse suas necessidades, dúvidas e interesses naquele momento.

Assim, no tocante a este adendo, excluindo-se o item ensino de leitura/ compreensão escrita, todos os outros assuntos foram indicados pelos licenciandos a partir da proposta de levantarem questões sobre o ensino de LE que, para eles, não haviam sido contempladas nas disciplinas que haviam cursado. As escolhas recaíram sobre: avaliação, ensino de produção oral, formação docente, internet e ensino de inglês, motivação, Prática Exploratória, produção e avaliação de material didático.

Entendo que esta forma de trabalhar a disciplina configura uma prática que revela minha crença de que, para a construção do profissional crítico, é preciso envolver todos, exercendo sua agentividade, em diversos momentos de tomada de decisão durante as aulas. Esclareço que ao referir-me ao construto crença, tomo-o no sentido proposto por Barcelos (2006:18), i.e.:

Uma forma de pensamento, como construções da realidade, maneiras de ver e perceber o mundo e seus fenômenos, co-construídas em nossas experiências e resultantes de um processo interativo de interpretação e (re)significação. Como tal, crenças são sociais (mas também individuais), dinâmicas, contextuais e paradoxais. 
Consequentemente, conforme apontam Barcelos e Kalaja (2003), as crenças podem mediar o processo de aprendizagem e de solução de problemas, porém não influenciando as ações diretamente. Por isso, no processo aqui relatado, certamente as crenças dos alunos professores também estiveram presentes. Percebo isto, por exemplo, na forma como receberam este tipo de proposta, i.e., embora todos tenham apreciado ver suas sugestões aproveitadas pela professora para compor o conteúdo da disciplina, alguns acharam tal forma de proceder muito diferente das práticas com as quais estavam acostumados. A própria forma como se inseriram na dinâmica das aulas de ESLI-II apontava para certa dificuldade em agir com mais agentividade, visto que pareciam presos a um modelo de condução dos processos apenas por parte do professor. Além disso, entendo que se caracterizava como crença a maneira como viam a escola campo de estágio. Esta, por ser da rede pública, já lhes trazia uma idéia de limitação e carência, o que em muitos aspectos não era referendado pela realidade. Assim, a partir das contribuições dos licenciandos, o curso foi estruturado e ministrado de forma que houvesse:

[a] aulas dedicadas à discussão de textos, ao planejamento de atividades e à sua implementação nas turmas de língua inglesa das escolas espaço de estágio;

[b] encontros individuais para acompanhamento das atividades de estágio;

[c] estágio supervisionado nas escolas de ensino médio onde os licenciandos desenvolveram atividades de observação, co-participação e prática (aulas ou oficinas, conforme solicitação das professoras-regentes e sob a orientação da professora de estágio supervisionado);

[d] reflexão sobre a prática do docente de língua inglesa.

Consoante com as orientações encontradas nos Parâmetros Curriculares Nacionais de Língua Estrangeira para o ensino fundamental (1998) e para o ensino médio (2000), a atividade do docente de língua estrangeira deve estar voltada para o desenvolvimento da competência de compreensão escrita dos aprendizes, embora não se limitando a ela, os licenciandos de ESLI-II, além da leitura dos PCN- LE (1998) e de textos que os ajudassem a compreender como elaborar unidades de leitura, selecionaram textos e planejaram aulas e unidades de leitura. Tanto as primeiras quanto as segundas foram debatidas em aula e, quando as professoras-regentes concordavam ${ }^{3}$, eram implementadas nas turmas de ensino médio. Esta foi, sem dúvida, uma grande oportunidade de aprendizagem [learning opportunity] (Allwright, 2005), uma vez que os licenciandos puderam observar a reação dos alunos, verificar de que forma os 
objetivos dos planejamentos foram atingidos ou o que dificultou a sua concretização. Puderam ainda avaliar se os critérios para planejamento e produção das atividades foram adequados para as séries e turmas nas quais estagiaram. Foi também uma instância de reflexão sobre a própria atuação docente em construção, dentre tantas outras questões que permeiam o planejamento e a implementação de tarefas de ensinoaprendizagem.

Durante as aulas de ESLI-II, à luz dos temas selecionados para o curso, os licenciandos e eu também refletimos sobre o planejamento de uma atividade para o desenvolvimento de produção oral, igualmente analisamos alguns exemplares de provas e de alguns livros didáticos. Além disso, refletimos sobre a interação professor-aluno no processo de socioconstrução de conhecimentos (Vygotsky, 1994, PCN-LE, 1998). Tal processo diz respeito à forma como o conhecimento é social e historicamente construído pelo par mais competente (na escola, via de regra é o professor) e o menos competente através de ações mediadas pela linguagem. Para Vygotsky $(1994: 111,112)$ há dois níveis de desenvolvimento resumidamente apresentados a seguir: [a] nível de desenvolvimento real - diz respeito às tarefas que o aprendiz já consegue desenvolver com autonomia, posto que refere-se a certos ciclos de desenvolvimentos já completados. Seria o desenvolvimento mental retrospectivamente observado; [b] nível de desenvolvimento potencial - este refere-se àquilo que o aprendiz só consegue fazer com o auxílio ou sob a orientação de outrem. Este autor (ibid.) propõe ainda o construto zona de desenvolvimento proximal. Esta seria a distância entre o nível de desenvolvimento real e o potencial, caracterizando o desenvolvimento mental de forma prospectiva, ou seja, ao atuar nesta zona, o par mais competente estaria trabalhando no sentido de co-construir a autonomia do aprendiz para que este solucione problemas independentemente. Há, portanto, segundo Vygotsky (ibid.: 75) um processo de internalização do conhecimento que acontece primeiro no nível social, ou interpsicológico, e, posteriormente, no nível pessoal, ou intrapsicológico. Trazendo tal teorização para o contexto da formação docente, seria trabalhar no sentido de coconstruir com os professores alunos uma base para a prática profissional com autonomia.

Edwards e Mercer (1987), alinhando-se a este entendimento vygotskiano sobre aprendizagem e aprofundando-o, apontam que é possível haver dois tipos de conhecimentos resultantes do processo de socioconstrução. O primeiro deles é o conhecimento ritualístico que tem uma natureza prática, uma vez que se permite que o 
aprendiz consiga resolver uma tarefa proposta. Assim, embora domine a estratégia para resolver tal atividade, não consegue transferir o conhecimento que o ajudou a solucionála para outra situação que difira daquela que está acostumado. Em contrapartida, o conhecimento de princípio tem a ver com a compreensão de como o conhecimento ritualístico funciona na resolução de tarefas. Ao fazê-lo, o aprendiz entende o que faz e porque faz, podendo transferir este conhecimento para situações diversas daquela que lhe propiciou a aprendizagem inicial. Diferentemente do primeiro conhecimento, conforme aponta Moita Lopes (1996), o aprendiz não faz uma busca pela resposta certa para agradar o professor. Segue-se que, no processo de formação docente, os professores aprendizes tanto devem ter consciência deste entendimento teórico não apenas para monitorar os processos de ensinar e aprender que se desenrolam na sala de aula, como o processo individual de construção de seus saberes profissionais.

O percurso de estágio nas escolas envolveu a construção de um olhar inicial, ao mesmo tempo reflexivo e de pesquisa com foco na ação docente, embasado nos princípios da Prática Exploratória (Allwright, 2001, 2003, 2005). No que diz respeito à proposta da PE, reitero que a pesquisa não deve envolver um problema a ser resolvido, mas uma questão ou puzzle que o praticante deseje entender (Moraes Bezerra, 2003). Em nossa interação, o puzzle orientador da dinâmica da disciplina ESLI-II se constituiu em um momento de revisão da crença de que é preciso 'agir para solucionar' uma vez detectado um problema. Consoante com a proposta da PE, o praticante deveria iniciar uma 'busca por entendimentos' a fim de poder dimensionar as questões envolvidas na configuração daquilo que se apresenta, ao menos inicialmente, como um problema, uma vez que o processo reflexivo pode permitir que se abra um novo prisma através do qual não se tenha um problema, mas um elemento que configure a qualidade de vida que se tem naquele contexto.

Assim, partindo desta proposta de 'olhar para entender', os licenciandos buscaram entrar no contexto de sala de aula tentando 'estranhar' o que já lhes era familiar e encontrar questões que pudessem conduzir este olhar de professor e de pesquisador em construção ${ }^{4}$. Desta forma, alguns dos questionamentos tematizados voltaram-se para: [a] tradução x ensino de leitura em língua inglesa; [b] o porquê de uma licencianda não ter ficado satisfeita com sua própria aula prática no estágio; [c] crenças docentes e discentes sobre o ensino de língua inglesa; [d] relações de afeto construídas entre licenciandas e alunas durante o estágio e como tal relação teve influência positiva na aula prática; [e] uso de estratégias de metacognição em aulas de leitura de língua inglesa 
e sua utilização em sala de aula de língua materna, dentre outras. Estas questões dimensionam como os olhares sobre o contexto de sala de aula apontam para o processo de construção de identidade profissional dos licenciandos, ao mesmo tempo em que refletem um diálogo intenso entre a bibliografia do curso e seus interesses pessoais de investigação. Como follow-up da atividade 'olhar para entender', solicitei aos licenciandos que preparassem pôsteres através dos quais pudessem partilhar com os colegas suas indagações e entendimentos. Durante a sessão de apresentação desses pôsteres, os professores alunos discorreram sobre suas questões, discutiram a revisão ou não de suas crenças de docentes em formação, mapearam suas ações no percurso de estágio - bem como as de professores e de alunos -, trataram do impacto de suas propostas de aulas práticas nas turmas em que estagiaram. Tudo isto possibilitou-lhes uma teorização inicial sobre os processos de ensinar e aprender derivados da prática docente em formação.

\section{ESTÁGIO: SOB O OLHAR DOS LICENCIANDOS}

Seguindo a tradição de estágios na área de Letras, os professores alunos do curso de Letras/FFP produzem relatórios das atividades desenvolvidas durante o estágio. Indo além do fator burocrático, vejo essa atividade como um momento para reflexão sobre a experiência vivida, as decisões tomadas e as ações desenvolvidas. Dentre os documentos que compõem o portfólio de estágio, os licenciandos preenchem relatórios de observação e de co-participação. Não é preciso redigir um formulário por aula, mas um formulário de observação e outro de co-participação contendo um resumo das atividades desenvolvidas durante o estágio. No portfólio, os licenciandos registram as suas experiências e percepções sobre o estágio e sobre a disciplina estágio supervisionado, constituindo-se um exercício retrospectivo de reflexão. Trata-se de uma oportunidade que os licenciandos têm a posteriori, se ainda não o fizeram durante o desenvolvimento das atividades, de estabelecer uma relação entre as propostas teórico-metodológicas, as aulas que eles planejam/implementam com a orientação da professora de ESLI-II e a prática da professora regente. Há, no modelo do documento, alguns itens que auxiliam o estabelecimento desta relação ${ }^{5}$.

Além disso, cabe enfatizar que o olhar dos licenciandos às aulas de língua inglesa é construído, nas aulas de estágio por mim ministradas, através dos princípios da Prática Exploratória (Allwright, 2001, 2003, 2005), conforme já apresentados, bem como pela 
perspectiva que tenho construído ao longo de minha vida profissional enquanto professora de inglês de ensino fundamental e médio. Tudo isto, obviamente, articulado aos entendimentos e às crenças que os licenciandos trazem para o processo. Assim, espera-se que eles busquem construir seus próprios entendimentos sobre a sala de aula de língua inglesa, problematizando suas vivências e articulando-as à base teórica estudada durante a graduação e, mais especificamente, àquela discutida durante as aulas de ESLI-II.

\title{
1. Leonardo e Lucíola: "The teacher focused on discourse"
}

Abaixo encontra-se o fragmento do relatório ${ }^{6}$ de dois licenciandos que desenvolveram o estágio na mesma turma e ao mesmo tempo. Vejamos o que puderam identificar e problematizar a partir da prática da professora regente durante o período de observação:

\begin{abstract}
In relation to how language was focused on the classes, we could notice the teacher focused on discourse in order to develop the students' reading ability. She used to ask them to do some exercises based on a specific type of text. For instance, once she brought a text about Airton Senna's biography. At that moment, she was dealing with texts about biography, and they were supposed to hand in a sheet of paper with the answers of the activities in the end of the class. They were supposed to work in pairs or group of four. Moreover, the teacher seemed to follow the orientations of PCN-LE. She asked the students to do activities based on several textual genres which were found in their social practices. On the other hand, she did not propose any discussion about the function or the characteristics of each textual genre worked. Her classes were based on these reading activities only. There was not a postreading to reinforce the specificities of the target genre. ${ }^{7}$ (Leonardo e Lucíola)
\end{abstract}

É possível perceber que as discussões sobre ensino de compreensão escrita e que o próprio planejamento de duas atividades de leitura pelos licenciandos durante as aulas de ESLI-II colaboraram para a construção deste olhar. Colaboraram ainda para que utilizassem construtos próprios de sua área de formação ao pensarem sobre a prática da professora. Vejamos alguns: discourse (discurso), reading ability (habilidade de leitura), post-reading (pós leitura), genre (gênero).

Percebe-se também que os licenciandos vão além da descrição das ações docentes quando problematizam o trabalho com leitura, delineando a utilização de um saber que se configura, acredito, como conhecimento de princípio (Edwards e Mercer, 1987). Fundamentados na proposta contida nos PCN-LE (1998) para o desenvolvimento da compreensão escrita, eles percebem que a professora regente, embora encaminhe seu trabalho a partir do desenvolvimento da habilidade de leitura de textos de diferentes 
gêneros - she asked the students to do the activities based on several genres which were found in their social practices - não discute funções e características dos gêneros com os quais trabalha, nem propõe atividades de pós leitura. Estas últimas seriam fundamentais para o estabelecimento de relações entre as questões presentes no texto e o mundo social discursivamente construído (Moita Lopes, 1996; Moita Lopes et al., 2005; Moraes Bezerra, 2007).

\section{Patricia: "I was always emphasizing the importance of reflection"}

O fragmento a seguir foi retirado do relatório de co-participação de Patrícia. Ela retrata o momento em que colaborou com a professora regente no desenvolvimento de uma atividade de produção textual com alunos do curso normal. Esta atividade envolvia a produção da capa de uma revista em inglês, bem como algumas páginas com fotos e algumas legendas naquele idioma. Considerando que a professora da turma desenvolvia o ensino de língua inglesa a partir do estudo de variados gêneros discursivos, o objetivo da atividade era o de levar os alunos a desenvolverem brevemente - utilizando-se de fotos e legendas - uma reportagem que houvessem definido para a capa de uma revista por eles criada, uma vez que a turma ainda não havia construído um conhecimento lingüístico/discursivo para a produção de parágrafos, por exemplo. Tal manchete teria a ver com o tema: Who am I? (Quem sou?) Who am I at school and in the world? (Quem sou na escola e no mundo?). Segundo a professora regente, tal atividade, fundamentada pelos princípios da PE, tinha por objetivo ajudá-la a entender seus alunos, seus pontos de vista sobre si próprios, sobre escola e questões sociais. Ao mesmo tempo, tinha por finalidade fazer com que os aprendizes refletissem sobre suas questões, trazidas para sala de aula. Estas estavam presentes nas práticas discursivas que modelavam o processo de ensino-aprendizagem de língua inglesa, trazendo conseqüências mais ou menos positivas para a qualidade de vida (Gieve e Miller, 2009) do grupo. A percepção que Patrícia construiu de tal proposta pode ser vista no trecho abaixo:

The most interesting of this activity was that the piece of news should be about [the] students' lives, they could choose a topic for this new but it should express their point of view about the topic, they could tell how they feel and what they think about it. In this activity, students would be in contact with the foreign language and improve their writing ability, but the most important, which was the teacher purpose, was make them reflect about situations they are in contact and their likes and dislikes. My function was directly related to 
this reflection, I went closer to their desk to check if they have some doubts, gave some ideas, helped them with some translations but I was always emphasizing the importance of reflection, making them to think about the reason of their choice and to show their opinion through the choice of the pictures. ${ }^{8} \quad$ - (Patrícia)

A professora com quem Patrícia desenvolveu suas atividades de estágio, embora mantivesse um foco maior sobre o desenvolvimento da compreensão escrita de seus alunos através da utilização de diversos tipos de textos, trabalhava também com a produção escrita - students [..] improve their writing ability - evidenciando uma contextualização da escrita.

Em um momento anterior a esta proposta, houve um trabalho inicial envolvendo a leitura de capas de revistas em inglês em que houve a participação da licencianda. Em ambos os casos, havia uma constante preocupação com a reflexão e com a formação do cidadão crítico imbricada nas tarefas. A licencianda estava engajada neste processo, juntamente com a professora e a turma, conforme é proposto pelo princípio da PE, que estende o processo de ação pedagógica para a construção de entendimentos a todos que estiverem no contexto; assim, na percepção da professora aluna: but my function was directly related to this reflection. Para Patrícia, esta proposta facilitou não apenas a sua aproximação com os alunos da turma, como também a oportunidade de exercer sua agentividade, funcionando como mediadora no processo de construção de conhecimentos. Além disso, parece ter sido uma oportunidade de aprendizagem (Allwright, 2005) no sentido de verificar in loco uma prática de ensinar focando o 'planejar para entender', orientada pelos princípios da PE, sem que a professora se afastasse da proposta de ensino contida em seu planejamento de curso.

Ressalto ainda o uso de 'but' na sentença citada acima. No texto original, essa conjunção é colocada após uma sequência de ações docentes desenvolvidas por Patrícia, juntamente com a professora regente, no período de co-participação para introduzir outra ação. Esta forma de estruturar seu texto, a partir desta pista de contextualização (Gumperz, [1992]1997, parece mostrar que toda a sequência didática estava a serviço de algo tão relevante quanto o aprendizado da língua estrangeira: a reflexão e questionamentos dos aprendizes sobre si e sobre o mundo social. 


\title{
3. Júlia e Liliana: “Cleide suggested us to deal with definite and indefinite articles"
}

O fragmento abaixo revela um momento de decisão de outra dupla de licenciandas - Júlia e Liliana - quanto ao planejamento de sua aula prática. Ao terem o assunto definido pela professora, i.e., um item gramatical, buscaram articulá-lo a uma proposta de leitura. Tal fato é de extrema relevância neste caso porque, diferentemente das professoras com as quais Patrícia, Leonardo e Lucíola desenvolveram as atividades de estágio, esta não trabalhava leitura com seus alunos. Seu foco recaía sobre itens gramaticais em frases isoladas ou em diálogos. Segue um trecho da narrativa das licenciandas em que mencionam tal questão:

\begin{abstract}
In relation to the class we carried out on July $3^{\text {rd }}$, Cleide suggested us to deal with definite and indefinite articles. She was the one who proposed this theme; nevertheless we had total freedom to choose how we would approach it. Thus, as it was the first time we would deal with this grammar topic in high school, we did not know how to engage students in our class. So, we asked for some suggestion to our orientation teacher in relation to how to develop our class in that public school in a way we could co-construct knowledge with students. For this reason, we decided to propose a reading class focusing on the theme of "animals illegally kept in captivity". During its pre-reading, we made some questions concerning students' contact with animals so that we could have a picture of the intensity of their living together with them in their daily life. ${ }^{9}$
\end{abstract}

(Júlia e Liliana)

O fato de Júlia e Liliana buscarem tratar do item gramatical em um texto aponta para um distanciamento, já na formação pré-serviço destas licenciandas, do modelo de ensino focado em estruturas gramaticais apenas, apresentadas em sentenças descontextualizadas ou em diálogos montados para este fim conforme aponta a literatura da área (Dutra e Melo, 2004; Moraes Bezerra, 2006, 2008). As professoras em formação caminham em direção a uma perspectiva de língua enquanto discurso e ferramenta de ação social (PCN-LE, 1998) através da utilização de gêneros - neste caso, uma pequena reportagem. Além disso, o tema da aula reforça esta questão por trazer para o espaço discursivo da sala de aula um assunto que, ao ser negociado nas interações, poderia promover a revisão de crenças e posicionamentos quanto à manutenção de determinados animais em cativeiro. Dessa forma, as licenciandas estariam tangenciando alguns temas transversais e colaborando no processo de construção de valores dos alunos.

Considerando que os professores aprendizes costumam iniciar o curso universitário, e frequentemente estabelecer uma prática docente (Moraes Bezerra, 
2008), partindo da crença de que é preciso dar ênfase ao ensino de línguas através de memorização, bem como de ter um foco em estruturas gramaticais dissociadas da utilização real nos diferentes gêneros discursivos, as alunas caminham no sentido da revisão e mesmo reconstrução da de tal crença. Com isto, também parece ter havido a construção de conhecimento de princípio (Edwards e Mercer, 1987) relevante para o estabelecimento de suas práticas, especialmente se for considerado o impacto de uma prática teoricamente informada e criticamente distanciada de modelos que costumam receber críticas. Aliás, as alunas tentaram inserir no contexto da sala de aula em que desenvolveram o percurso de estágio uma possibilidade de trabalho com a língua enquanto discurso. Elas não se limitaram à avaliação das ações da professora regente cuja proposta de trabalho fundamentava-se no foco na forma. Possivelmente esta colega só tivera contato com o modelo de aula de língua estrangeira calcado em estruturas gramaticais. Além disso, talvez sua formação profissional não tenha contemplado um trânsito pelas questões teóricas e metodológicas que foram disponibilizadas a estas licenciandas, tais como ensino de leitura em LE, produção de unidades de leitura, a formação do professor reflexivo, ensino de gramática a partir de uma perspectiva discursiva, dentre outras. Tal atitude de Júlia e Liliana, por isso, poderia contribuir para a formação continuada da professora regente.

\section{Salete e Vanesca: “The way the teacher developed the activities was very different for us"}

Tratando agora da experiência de duas outras licenciandas - Salete e Vanesca -, é possível dizer que a sala de aula de língua inglesa reservou algumas surpresas para ambas como pode ser observado pelo fragmento abaixo:

\footnotetext{
The way the teacher developed the activities was very different for us, but, on the other hand, it was very interesting. She made a mix with others subjects asking them question about Geography, Biology, Math and History. The interesting fact that we had to admit is that we had more doubts to do the exercises than the students, because it is a different way to work and we did not have exercises like that when we were studying at school. ${ }^{10}$
}

A proposta pedagógica da professora-regente embora não contemplasse a compreensão de textos escritos, não estava limitada ao ensino de itens gramaticais. Em uma tentativa de atrelar o ensino de inglês a outros conteúdos e de acionar o conhecimento de mundo (PCN-LE, 1998) dos aprendizes, as atividades propostas 
focavam conceitos e informações vindos de outras disciplinas - geografia, biologia, matemática e história. Agindo assim, a colega parecia trabalhar a partir de princípios que apontam para a abordagem denominada Content-Based Instruction (Richards e Rodgers (2001).

De certa forma as licenciandas vêem-se no entrelugar de alunas - ao afirmarem que "tinham mais dúvidas sobre como fazer os exercícios do que os alunos” (we had more doubts to do the exercises than the students) - e, ao mesmo tempo, de profissionais em formação ao olharem a prática docente da professora regente, tentando encontrar eco para a experiência que vivenciavam através do acesso ao aparato teóricometodológico sobre ensino-aprendizagem de línguas que haviam construído até então. Acredito que tal experiência tenha apontado para a possibilidade de haver múltiplas configurações pedagógicas para o ensino de idiomas na trajetória de formação inicial das duas licenciandas. Da mesma forma, a experiência de estágio as fez rever possíveis crenças acerca do que poderia ser considerado como um frame de aula de inglês.

\section{POSSÍVEIS ENTENDIMENTOS}

Embora não tenha conseguido traduzir em palavras tudo o que foi desenvolvido durante as aulas e encontros individuais, assim como nas escolas onde os estágios se concretizaram, acredito ter sido possível apresentar algumas das oportunidades de aprendizagem (Allwright, 2005) vivenciadas pelos licenciandos, das quais aponto três instâncias.

Em primeiro lugar, foi possível resgatar dos fragmentos retirados dos relatórios marcas lingüísticas apontando não apenas para a apropriação de construtos pertinentes à sua área de formação profissional, mas também para o uso dos mesmos a fim de fundamentar uma reflexão que revelou um olhar teoricamente informado ao contexto de sala de aula e às práticas docentes. Em segundo, parece que houve a construção de conhecimento de princípios (Edwards e Mercer, 1987) relativos à área profissional de atuação, especialmente devido às explicações que se seguiam à problematização das questões com as quais se depararam no percurso de estágio. Em terceiro lugar, permitiu que vivenciassem e partilhassem, em nossas discussões, suas leituras sobre como professores diferentes, fruto de diferentes processos de formação, conduziam suas práticas, especialmente aqueles que operavam a partir da proposta de leitura. 
Para mim, professora do grupo, configurou-se em mais um momento de reflexão profissional sobre vários aspectos especialmente as possíveis contribuições para o processo de formação docente inicial na medida em que foi aberto um espaço para que juntos - licenciandos e eu - definíssemos o que ler e como conduzir as aulas e os encontros para orientação. Da mesma forma, as discussões geradas em sala de aula pelas leituras mais uma vez fizeram-me não apenas ratificar o lugar teórico que assumo como fundamento de minha prática pedagógica, mas, ao mesmo tempo, desenvolver o trabalho discursivo de explicitá-lo, de argumentar sobre ele, respondendo a questionamentos de licenciandos. Este processo levou-me a redimensionar os saberes que tenho construído na interface das questões trazidas por cada um. Da mesma forma revelou um exercício de construção de conhecimento de princípio (ibid.) em minha trajetória de formação continuada que se faz presente paralelamente ao meu trabalho docente.

Por isso, termino com um fragmento do relatório de Júlia e de Liliana no qual refletem sobre a experiência durante o estágio. Assim, elas afirmam:

Therefore, this English training has been very important to our career as English teachers, once we could be in touch with real classroom interaction in which we could rethink that context keeping in mind some reflections we have been having throughout Liberal Arts course. In other words, it was worthwhile to take part of the English teacher training seeing that it enabled us to be immersed in the complexity of an English language classroom with some of the uncertainties it involved. ${ }^{11}$

Neste trecho, elas apontam para a importância do estágio no processo de formação inicial como docentes de língua inglesa devido à complexidade imanente ao processo de ensino-aprendizagem de um idioma e da vida em sala de aula. Especialmente a última sentença do fragmento parece ecoar as vozes dos praticantes da PE, talvez um reflexo das leituras e discussões sobre esta forma de estar e agir em sala de aula.

Creio, portanto, que muito ainda precise ser pensado por professores formadores e pelos licenciandos no sentido de melhor aproveitarem as múltiplas experiências que as salas de aulas de aula de língua inglesa oferecem. Da mesma forma, é preciso repensar como a figura do professor regente é vista neste processo; afinal, ele também é formador do professor iniciante. Consequentemente, ações no sentido de aproximar a universidade das escolas campo de estágio são cruciais para que esta conversa profissional entre todos esses segmentos seja fortalecida e aprofundada. 


\section{Notas}

1 Uma versão embrionária e menos extensa deste trabalho, no formato relatório, foi entregue à Coordenação de Estágio da FFP. Agradeço ainda aos meus queridos alunos, pois, sem suas reflexões sobre estágio aqui relatadas, não seria possível pensar sobre formação docente.

2 Cabe informar que, na grade do curso Português-Inglês, há disciplinas com foco específico no ensino de língua inglesa desde o quarto período de formação.

${ }^{3}$ Embora, nos PCN-LE (1998), os docentes encontrem a orientação de que a atividade de ensino de língua estrangeira deva estar pautada pela utilização de diferentes tipos de textos, privilegiando a construção do leitor crítico, nossa experiência com professores da rede pública evidencia que ainda há muitos colegas que trabalham a partir de um entendimento de língua enquanto ensino de estrutura, ou seja, de itens gramaticais, em frases isoladas (Moraes Bezerra, 2000; Dutra e Mello, 2004).

${ }^{4}$ Os proponentes dos PCN-LE (1998) advogam a formação do professor pesquisador desde a graduação. Assim, esta é uma das vertentes teóricas na qual me apoio no sentido de fomentar a prática da atividade de ensino aliada à de pesquisa.

5 Tal proposta não é feita com o objetivo de criticar, nem encontrar problemas na prática docente das colegas que aceitam nossos estagiários em sua sala de aula. Na verdade, é preciso registrar nosso agradecimento a estes colegas, pois, sem sua receptividade, nossos alunos não teriam onde vivenciar este momento de sua formação profissional.

${ }^{6}$ Embora os fragmentos selecionados possam conter alguns problemas com relação ao idioma escrito, opto por respeitar o texto original em inglês produzido pelos alunos. Nomes fictícios foram utilizados para identificar os licenciandos.

${ }^{7}$ Em relação à maneira como a língua era trabalhada nas aulas, notamos que a professora focava no discurso a fim de desenvolver a habilidade de leitura dos alunos. Ela costumava pedir-lhes que fizessem alguns exercícios baseados em algum tipo de texto. Por exemplo, uma vez ela trouxe uma biografia do Airton Senna. Naquele momento, ela estava trabalhando com textos sobre biografias e eles deveriam entregar uma folha com as respostas das atividades ao final da aula. Eles tinham que trabalhar em pares ou em grupos de quatro.

Além disso, a professora parecia seguir as orientações dos PCN-LE. Ela pedia aos alunos para fazerem atividades baseadas em diversos gêneros textuais que eles encontram em suas práticas sociais. Por outro lado. Ela não propunha qualquer discussão sobre a função ou características de cada gênero textual trabalhado. Suas aulas eram baseadas apenas nas atividades de leitura. Não havia pós-leitura para reforçar as especificidades do gênero alvo.

${ }^{8} \mathrm{O}$ mais interessante nesta atividade é que a reportagem de capa poderia ser sobre a vida dos alunos. Eles poderiam escolher um tópico para esta reportagem mas ela deveria expressar o seu ponto de vista sobre o tópico. Eles podiam dizer como se sentiam e o que pensavam sobre ele. Nesta atividade, os alunos estariam em contato com a língua estrangeira e desenvolveriam sua habilidade de produção escrita, mas o mais importante, que era o objetivo da professora, era fazê-los refletir sobre situações por eles vivenciadas e sobre o que gostam ou não. Minha função estava diretamente ligada a esta reflexão. Eu me aproximei dos alunos para verificar se eles tinham dúvidas, para dar algumas sugestões, para ajudá-los em algumas traduções mas eu estava sempre enfatizando a importância da reflexão, fazendo-os pensar sobre a razão de suas escolhas e apresentar suas opiniões através da escolha das figuras.

${ }^{9}$ Em relação à aula que implementamos no dia 3 de julho, Cláudia sugeriu que trabalhássemos com artigos definidos e indefinidos. Foi ela quem propôs o tema, contudo nos deu a liberdade de escolhermos como seria a abordagem. Desta forma, como era a primeira vez que ensinaríamos um tópico gramatical no ensino médio, não sabíamos como envolver nossos alunos em aula. Assim, pedimos uma sugestão à nossa professora Isabel Cristina em relação a como desenvolver nossa aula em escola pública de forma que pudéssemos co-construir conhecimento com nossos alunos.

Por esta razão, decidimos propor uma aula de leitura focando no tema "animais mantidos ilegalmente no cativeiro”. Durante a pré-leitura, fizemos algumas perguntas com relação ao contato dos alunos com animais de forma a ter uma idéia da intensidade da proximidade entre eles em sua vida cotidiana.

${ }^{10}$ A forma como a professora desenvolveu as atividades foi muito diferente para nós, mas, por outro lado, foi muito interessante. Ela fez uma relação com outras disciplinas, fazendo perguntas sobre geografia, biologia, matemática e história. O fato interessante que precisamos admitir é que tínhamos mais dúvidas que os alunos para responder às atividade porque é uma forma diferente de se trabalhar e nós não tivemos exercícios como estes quando estudávamos na escola.

${ }^{11}$ Portanto, a prática no estágio de inglês foi muito importante para nossa carreira como professoras de inglês, uma vez que pudemos ter contato com interação em sala de aula real na qual pudemos repensar sobre aquele contexto mantendo em mente algumas reflexões que vínhamos fazendo ao longo do curso de 
Letras. Em outras palavras, foi válido participar do estágio vendo que ele nos permitiu estar imersas na complexidade de uma sala de aula de língua inglesa com algumas das incertezas que isto envolve.

\section{REFERÊNCIAS}

Abrahão, M. H. V. (2002). Teoria e prática na formação pré-serviço do professor de língua estrangeira. In Gimenez, T. (org.) Trajetórias na formação de professores de línguas. Londrina: Ed. UEL, 2002.

Allwright, D.(2005). From 'Teaching Points' to 'Learning Opportunities', and Beyond. TESOL QUARTERLY, v.39, n.1.

(2003). Exploratory Practice: rethinking practitioner research in language teaching. In: Language Teaching Research 7, 2.

. (2001). Learning (and teaching) as well as you know how: why is it so very difficult? In: Wagner, J. (ed.) Pcedagogik og læring I fremmed - og andetsprog. Odense Working Papers in Language and Communication, n. 22.

Allwright, D.; Hanks, J. T. (2009). The Developing Language Learner - An Introduction to Exploratory Practice. London, New York: Palgrave, Macmillan.

Barcelos, A. M. F. (2006). Cognição de professores e alunos: tendências recentes na pesquisa de crenças sobre ensino e aprendizagem de línguas. In Barcelos, A. M. F.; Abrahão, M. H.V. (Orgs.) Crenças e Ensino de Línguas - foco no professor, no aluno e na formação de professores. Campinas: Pontes Editores, p.15-42.

Barcelos, A. M. F.; Kalaja, P. (2003). Conclusion: Exploring possibilities for future research on beliefs about SLA. In: Kalaja, P.; Barcelos, A. M. F. (orgs.) Beliefs about SLA: New Research Approaches. Dordrecht: Kluwer, p. 231-238,

BRASIL. (2000). Ministério da Educação e Secretaria de Educação. Parâmetros Curriculares Nacionais - PCN Ensino Médio. Brasília: MEC; SEMTEC.

BRASIL. (1998). Ministério da Educação e Secretaria de Educação. Parâmetros Curriculares Nacionais: terceiro e quarto ciclos do ensino fundamental: língua inglesa / Secretaria de Educação Fundamental - Brasília: MEC/SEF.

Dutra, D. P.; Mello, H. (2004). Os caminhos do ensino de gramática em línguas estrangeiras. In: Dutra, D. P.; Mello, H. (orgs.) Gramática e o Vocabulário no Ensino de Inglês: novas perspectivas. Belo Horizonte: Faculdade de Letras da UFMG, POSLIN..

Edwards, D., Mercer, N. (1987). Common Knowledge. London: Routledge. 
Filipe, F. R.(2009). Não teria sido mais fácil se você tivesse oferecido um modelo? Repensando a construção do plano de aula. Dissertação de Mestrado inédita, PUC-Rio.

Gieve, S.; Miller, I. K. (2006). What do we mean by 'Quality of Classroom Life'? In: Gieve, S.; Miller, I. K. (ed.) Understanding the language classroom. Hampshire: Palgrave Macmillan, 18-46.

Gimenez, T. (2004). Tornando-se professores de inglês: experiências de formação inicial em um curso de Letras. In: Abrahão, M. H. V. Prática de Ensino de Língua Estrangeira: experiências e reflexões. Campinas: Pontes Editores, ArteLíngua, p. 171187.

Gumperz, J. J. ([1992]1997) Contextualization and understanding. In Goodwin, C.; Duranti, A. (eds.) Rethinking Context. Cambridge: Cambridge University Press, p.229252.

Kushnir, A. N.; Machado, B. S. (2003). Puzzling, and puzzling about puzzle development. In: Language Teaching Research 7, London: Arnold, 163-180.

Miller, I. K.(2001). Researching teacher consultancy via Exploratory Practice: a reflexive and socio-interactional approach. Tese de doutorado inédita, Lancaster University.

Miller I. K. et al. (2008). Prática Exploratória : questões e desafios. In: Gil. G.; VieiraAbrahão, M. H. Educação de Professores de Línguas - os desafios do formador. Campinas: Pontes Editores, 145-165.

Moita Lopes, L. P. (1996). Oficina de Linguística Aplicada. Campinas: Mercado de Letras.

Moita Lopes, L. P. et al. (2005). Línguas Estrangeiras. In: Reorientação Curricular. Secretaria de Estado de Educação do Estado do Rio de Janeiro, 87-122.

Moraes Bezerra, I. C. R. (2000). Formação de Professores de Inglês: embate e caminhos na construção do conhecimento e da identidade profissional. Dissertação de Mestrado, UFRJ, Rio de Janeiro.

.(2003). Prática Exploratória: um caminho para o entendimento. In: Pesquisas em Estudos Pedagógicos. RJ: IPEL - PUC-Rio, vol. 2 (2).

- (2006). Teoria e Prática: os dois lados da moeda nas aulas de prática de ensino. In: Botelho, J. M. Estudos Reunidos: Linguagem, Literatura e Estilística. Rio de Janeiro: Botelho, p. 127-143.

(2007a) Prática de Ensino de Inglês: Quando a Teoria e a Prática Buscam o Diálogo. In: Abrahão, M. H. V.; Gil, G.; Rauber, A. S. (orgs.) Anais do I Congresso Latino-Americano sobre Formação de Professores de Línguas. Florianópolis: UFSC. Disponível em CD-ROM. 
(2007b). "Com quantos fios se tece uma reflexão?”

Narrativas e argumentações no tear da interação. Tese de doutorado inédita, PUC-Rio.

(2008). “Eu acho impossível colocar em prática, mas eu queria”: pensando em uma abordagem de gêneros para o ensino de inglês. In: Soletras Linguagens, Identidades, Ensino: Modos de pensar, modos de fazer. Revista do Departamento de Letras - Faculdade de Formação de Professores. São Gonçalo: UERJ. Ano 8, $\mathrm{n}^{\circ}$ 16, jul./dez. Suplemento. Disponível em www.filologia.org.br/soletras/16sup/linguagens.pdf

Moraes Bezerra, I. C. R.; Miller, I. K. de. (2006). Professores de inglês envolvidos na socioconstrução discursiva de seus entendimentos: o espaço da Prática Exploratória. Figueiredo, F. J. Q. de. (Org.) Anais do VI Seminário de Línguas Estrangeiras. Goiânia: UFG, CD-ROM, p. 258-268.

Parâmetros Curriculares Nacionais: terceiro e quarto ciclos do ensino fundamental: língua inglesa / Secretaria de Educação Fundamental - Brasília: MEC/SEF, 1998.

Parâmetros Curriculares Nacionais Ensino Médio. (2000)

Richards, J. C.; Rodgers, T. S. (2001). Approaches and Methods in Language Teaching. Cambridge: Cambridge University Press.

Santiago, A.C.S. (2009). Quem sou eu, quem somos nós? Membros do grupo de Prática Exploratória buscando entender suas próprias narrativas de experiências. Dissertação de Mestrado. PUC-Rio.

Silva, C. B. (2008). "Why my students don't want to learn English?” - Understanding students' beliefs. Rio de Janeiro: PUC, Departamento de Letras, monografia de especialização.

Vygotsky, L. S. (1994). A Formação Social da Mente. São Paulo: Martins Fontes.

\section{A AUTORA}

Isabel Cristina R. Moraes Bezerra é doutora em Letras (Estudos da Linguagem) pela PUC-Rio. Atua como professora adjunta na Faculdade de Formação de Professores/UERJ. Seus interesses de pesquisa envolvem análise do discurso profissional, ensino/aprendizagem de língua inglesa, construção de conhecimento e de identidade docente, produção de material didático.

E-mail: icmoraes@uol.com.br 